\title{
Classificando Dados de Evasão do Curso de Matemática da Universidade Estadual do Oeste do Paraná - Campus Cascavel
}

\author{
Aldioni Adaiani Andreta $\underline{\text { Rosangela Villwock }}$ \\ Universidade Estadual do Oeste do Paraná \\ Campus de Cascavel, PR \\ E-mail: \{aldioniadaiani, rosangelamat\}@ hotmail.com
}

\begin{abstract}
RESUMO
A evasão no ensino superior, segundo Silva Filho et al. (2007), é um problema de nível internacional que afeta o resultado dos sistemas educacionais. As perdas, relacionadas a estudantes que iniciam um curso, mas não o concluem, representam desperdícios sociais, acadêmicos e econômicos. No setor público, representa recursos públicos investidos sem o devido retorno.

Souza (2008) relata que as causas para a evasão podem ir desde um impedimento ou dificuldade séria, à falta de motivação ligada à própria realização do curso ou ao contexto sócioindividual ou do ambiente.

Gaioso (2005) apresenta alguns problemas que levam a evasão, indicados pelos alunos: falta de orientação vocacional, imaturidade do estudante, reprovações sucessivas, dificuldades financeiras, falta de perspectiva de trabalho, ausência de laços afetivos na universidade, ingresso na faculdade por imposição familiar, casamentos não planejados e nascimento de filhos.

Como em muitas outras universidades, o alto número de abandonos é uma realidade na Universidade Estadual do Oeste do Paraná - UNIOESTE. No curso de Licenciatura em Matemática são oferecidas 40 vagas anualmente para ingresso de estudantes no período noturno. O número de conclusões a cada ano no curso é muito baixo e o número de alunos que abandonam o curso é elevado, 132 abandonos nos últimos cinco anos (2008-2012).

Diante disso, este trabalho teve por objetivo investigar aspectos sociais e econômicos dos acadêmicos do curso de Matemática da UNIOESTE - campus de Cascavel que possam ter influencia na tomada de decisão de abandonar o curso.

Os dados utilizados para o desenvolvimento deste trabalho foram coletados via questionário aplicado aos acadêmicos que estavam matriculados no curso no ano de 2012 (ainda matriculados em 2013 ou que abandonaram o curso em 2012). O questionário aplicado aos acadêmicos abordou questões socioeconômicas como renda familiar, participação no orçamento doméstico, gasto com a graduação, cidade de residência, moradia, entre outras. Para este trabalho, 41 pessoas responderam o questionário, sendo que 32 estão matriculados em 2013 e nove evadiram em 2012.

Dentre os acadêmicos pesquisados, a maioria reside em Cascavel, são solteiros, possuem renda familiar de três a cinco salários mínimos, contribuem no orçamento domestico, gastam entre 50 e 300 reais com a graduação, estudam entre 10 e 30 horas por semana fora da sala de aula e trabalham seis ou mais horas por dia.

$\mathrm{Na}$ busca por informações úteis na base de dados criada utilizou-se uma técnica de Mineração de Dados. Para Tan et al.(2009), a mineração de dados consiste em um conjunto de conceitos e métodos com o objetivo de encontrar uma descrição, preferencialmente compreensível e interessante para o usuário, de padrões e regularidades em um determinado conjunto de dados.

A tarefa de Mineração de Dados foi a Classificação. Os padrões (acadêmicos) foram rotulados como evadidos e não evadidos. As variáveis são fatores que poderiam influenciar os acadêmicos na tomada de decisão de abandonar o curso. Segundo Tan et al. (2009) a Classificação tem a função de encontrar regras que predizem a classe em função dos atributos. No caso deste trabalho, predizer a decisão de abandonar o curso em função de variáveis relativas aos fatores socioeconômicos.
\end{abstract}


Para realização deste trabalho utilizou-se o software WEKA - Waikato Environment for Knwoledge Analysis ${ }^{l}$, aplicando-se o algoritmo J48 para obter Árvores de Decisão. Fazendo a interpretação da Árvore de Decisão gerada, conclui-se que o acadêmico que não trabalha não abandona o curso. Esta regra foi alcançada por 28 acadêmicos e não foi válida para apenas dois. Desta forma, o fato de não trabalhar foi um fator relevante para a permanência no curso.

A segunda variável mais relevante foi o estado civil. Se além de trabalhar o acadêmico for casado, o mesmo abandonou o curso. Esta regra foi alcançada por três acadêmicos. Por fim, a idade também teve contribuição para a evasão, visto que acadêmicos que trabalhavam e não eram casados mas que tinham idade maior de 24 anos decidiram por abandonar o curso. Esta regra foi alcançada por cinco acadêmicos e não foi válida para apenas um.

Analisando os resultados concluiu-se que o fator trabalho é o de maior relevância na decisão de abandonar o curso. Acredita-se que isso se deve ao fato de que o acadêmico que trabalha (para se sustentar ou sustentar a família) tem pouco tempo para dedicar-se ao estudo extraclasse.

Apesar de triviais, as regras encontradas referendam aquilo que, por convívio com os acadêmicos envolvidos na pesquisa, se esperava. Espera-se com este trabalho poder contribuir para elaborações de políticas que visem atender as necessidades dos acadêmicos, podendo garantir a permanência dos mesmos na Universidade.

Como sugestão para trabalhos futuros pode-se citar a identificação das disciplinas que mais reprovam, a identificação de fatores que podem influenciar no alto índice de reprovações nestas disciplinas, além de estudar o perfil dos alunos concluintes do curso.

Palavras-chave: Evasão no Ensino Superior, Mineração de Dados, Classificação, Árvores de Decisão

\section{Referências}

[1] N. P. L. Gaioso, "O fenômeno da evasão escolar na educação superior no Brasil”, 2005, 75 f, Dissertação (Mestrado em Educação) - Programa de Pós-Graduação em Educação da Universidade Católica de Brasília, Brasília, 2005.

[2] R. L. L. E. Silva Filho; P. R. Motejunas; O. Hipólito; M. B. de C. M. A. Lobo, A Evasão no Ensino Superior Brasileiro, Cadernos de Pesquisa, v. 37, n. 132, p. 641 - 659, 2007.

[3] S. L. Souza, "Evasão no Ensino Superior: Um Estudo Utilizando a Mineração de Dados como Ferramenta de Gestão do Conhecimento em um Banco de Dados Referente à Graduação de Engenharia”, Dissertação de Mestrado, Coppe - UFRJ, Rio de Janeiro, 2008.

[4] P - N. Tan; M. Steinbach; V. Kumar, "Introdução ao Data Mining Mineração de Dados", Rio de Janeiro, Editora Ciência Moderna Ltda., 2009.

\footnotetext{
${ }^{1}$ Disponível em http://www.cs.waikato.ac.nz/ml/weka/index.html.
} 